\title{
CHEMICAL MODIFICATION OF CARBOXYL GROUPS IN GLUCOAMYLASE FROM ASPERGILLUS NIGER
}

by

\author{
BIRTE SVENSSON, HANNE MØLLER ${ }^{1)}$ and ANTHONY J. CLARKE ${ }^{2)}$
}

\author{
Department of Chemistry, Carlsberg Laboratory, \\ Gamle Carlsberg Vej 10, DK-2500 Copenhagen Valby \\ Present addresses: "Procos A/S, Bregneredvej 144, DK-3460 Birkerød \\ ${ }^{2}$ Department of Microbiology, University of Guelph, Guelph, \\ Ontario, Canada NIG 2WI
}

\begin{abstract}
Keywords: Water-soluble carbodiimide, ethylenimine, acarbose, difference spectroscopy, differential labelling
\end{abstract}

Glucoamylases G1 and G2 from Aspergillus niger lost the catalytic activity by prolonged treatment with 1-ethyl-3-(4-azonia-4,4-dimethylpentyl)carbodiimide(EAC). A total of 23 and 16 carboxyl groups were substituted out of 71 and 54 present in the G1 and G2 enzyme, respectively. The kinetics and the pH-dependence of the inactivation were compatible with the existence of one essential carboxyl group with a pK, 5.5. The inhibitor acarbose (a pseudotetrasaccharide) and the substrate maltose prevented EAC-modification of 4 and 2 carboxyl groups, respectively, with considerable retention of enzyme activity. Following removal of these ligands, differential labelling of critical carboxyl residue(s) was achieved by means of [ $\left.{ }^{3} \mathrm{H}\right] \mathrm{EAC}$.

Glucoamylase G2 with 12 EAC groups incorporated, prepared in the presence of acarbose, displayed a two-fold increase of $K_{m}$ and a slight reduction of $V_{m a x}$ for hydrolysis of starch relative to the unmodified enzyme. Both $K_{m}$ and $V_{\max }$ for hydrolysis of maltose were almost unaffected. In addition, maltose and three inhibitors perturbed the UV absorbance spectrum of this derivative. An altered shape of the acarbose-induced difference spectrum implied substitution of a carboxyl group near a binding tryptophanyl residue at a distance from the catalytic site. Efficient protection by acarbose against only the second part of the biphasic course of inactivation similarly reflected that residues playing different roles in the mechanism of action reacted with EAC.

In separate experiments, evidence was obtained for a preferred reaction of ethylenimine with enzymatically important carboxyl groups in glucoamylase.

\section{INTRODUCTION}

Chemical modifications have suggested that carboxyl groups in the different carbohydrases, $\alpha$-amylase (33), $\beta$-amylase (28), glucoamylase (17), pullulanase (39), $\alpha$-glucosidase $(32,61)$, trehalase (55) and sucrase-isomaltase (7) participate in the catalytic hydrolysis of starch and related compounds. The reaction between $\mathrm{Gl}$ and $\mathrm{G} 2$ glucoamylase (EC 3.2.1.3; 1,4-a-glucan glucohydrolase) from Aspergillus niger and wa-

Abbreviations: $\mathrm{CMC}=1$-cyclohexyl-3-(2-morpholinoethyl)carbodiimide; EAC = 1-ethyl-3-44-azonia-4,4dimethylpentyl)carbodiimide; EDC = 1-ethyl-3-(3-dimethylaminopropyl)carbodiimide; $\mathrm{Mes}=2-(\mathrm{N}$-morpholino)ethane sulfonic acid; Tris = 2-amino-2(hydroxylmethyl)-1,3-propandiol. 
ter-soluble carbodiimides has now been investigated in detail to enhance the knowledge of the roles played by carboxyl groups in substrate binding and catalysis. The two enzyme forms that differ in their C-terminal regions $(49,51)$ are equally active on soluble substrates, however, only the larger one, G1, can hydrolyse raw starch (52).

Glucoamylases catalyse the release of $\beta$-glucose from non-reducing ends of the substrates. Six consecutive glucosyl residues of a substrate chain can be accomodated at binding subsites and catalytic hydrolysis takes place between subsites 1 and 2(21). The chemical modification of glucoamylases from Rhizopus sp. (30) and A. saitoi (27) in the presence of substrates or inhibitors has previously led to the suggestion that the essential carboxyl groups are located at or near subsites 2 and 3. Crystals suitable for structural analysis have not been obtained from a glucoamylase, but substantial sequence homology exists $(29,53)$ between the enzymes from A. niger $(6,50,51), \mathrm{Rh}$. oryzae (4), S. cerevisiae (diastaticus) (60), Saccharomycopsis fibuligera (29) and S. cerevisiae (59). Residues in two of the four regions that are well-conserved have been assigned important functions (15, 48). On the basis of sequence similarities it has been hypothesized that glucoamylases share key structural features in their active site regions both with $\alpha$-amylases of known three-dimensional structure $(8,37)$ and a number of other starch- and maltodextrin-degrading enzymes $(15,45,48)$. In the light of this situation it was attempted to obtain chemical evidence for functional carboxyl groups in the enzyme from A. niger, which is the best characterized fungal glucoamylase.

\section{MATERIALS AND METHODS}

\subsection{Materials}

Glucoamylases G1 and G2 from Aspergillus niger were purified as described (52) from a commercial enzyme preparation, AMG $200 \mathrm{~L}$, supplied by Novo Industries, Bagsvaerd, Denmark.

1-Ethyl-3-(3-dimethylaminopropyl)carbodiimide (EDC), 1-cyclohexyl-3-(2-morpholinoethyl)carbodiimide (CMC), glycine ethyl ester hydrochloride, norleucine methyl ester hydrochloride, 3-nitrotyrosine ethyl ester hydrochloride, maltitol, and potato starch were from Sigma, St. Louis, MO. 1-Ethyl-3-(3-trimethylaminopropyl)carbodiimide (1-ethyl-3-(4-azonia-4,4-dimethylpentyl)carbodiimide, EAC) was synthesized from EDC and iodomethane according to a published procedure (44). $\left[{ }^{3} \mathrm{H}\right] \mathrm{EAC}$ was similarly synthesized employing $\left[{ }^{3} \mathrm{H}\right]$ iodomethane $\left(13 \mathrm{Ci} \times \mathrm{mmol}^{-1}\right.$, Amersham International, Amersham, England). The specific activity for different batches of $\left[{ }^{3} \mathrm{H}\right] \mathrm{EAC}$ varied in the range $0.5-2.5 \mu \mathrm{Ci} \cdot \mu \mathrm{mol}^{-1}$. $\left[{ }^{14} \mathrm{C}\right]$ Glycine ethyl ester hydrochloride $(52.3$ $\mathrm{mCi} \mathrm{mmol}^{-1}$ ) was from New England Nuclear, Boston, MA. Merck, Darmstadt, FRG, supplied maltose monohydrate, glucono-1,5-lactone, "System Glucose" kit, iodomethane and hydroxylamine hydrochloride. Ethylenimine was a laboratory preparation. Acarbose (Bay g 5421) (57) was the generous gift of Drs. E. TruSCHEIT, E. MölleR, and D. SCHMidT, Bayer AG, Wuppertal, FRG.

\subsection{Methods}

\subsubsection{Chemical modifications}

Glucoamylases $\mathrm{G} 1$ and $\mathrm{G} 2$ were treated with $\mathrm{EAC}, \mathrm{EDC}$, or $\mathrm{CMC}$ in $0.1 \mathrm{M}-\mathrm{Mes}$ at room temperature (10), either in the absence or in the presence of nucleophiles. During the reaction the $\mathrm{pH}$ was maintained at 6.0 or 4.7 . Aliquots were removed at appropriate time intervals, quenched by addition of a 3-fold molar excess over carbodiimide of $1 \mathrm{M}$-sodium acetate $\mathrm{pH} 4.3$ and the remaining activity towards maltose was measured after exhaustive dialysis against 0.05 M-sodium acetate $\mathrm{pH}$ 4.3.

Differential labelling comprised an initial carbodiimide treatment in the presence of either acarbose or maltose. Following removal of the ligand by dialysis (the enzyme-acarbose complex being first dissociated by exposure to 1.7 $\mathrm{M}$-Tris- $\mathrm{HCl} \mathrm{pH} \mathrm{7.6(15)),} \mathrm{inactivation} \mathrm{was} \mathrm{subse-}$ quently attempted by either $\left[{ }^{3} \mathrm{H}\right] \mathrm{EAC}$ alone or EDC plus $\left[{ }^{14} \mathrm{C}\right]$ glycine ethyl ester, 3-nitrotyrosine ethyl ester or norleucine methyl ester.

Ethylenimine modifications were carried out by treatment of glucoamylase $\mathrm{G} 1\left(1-50 \mathrm{mg} \cdot \mathrm{ml}^{-1}\right)$ in water at $\mathrm{pH} 5.7$ with 20-1400-fold molar 
excess of reagent for $24 \mathrm{~h}$ essentially as earlier described (58). Excess reagent was removed by dialysis prior to determination of the extent of modification and remaining enzymic activity (see 2.2.2).

\subsubsection{Analytical procedures}

Concentrations of glucoamylase G1 and G2 were determined spectrophotometrically using the molar extinction coefficients at $280 \mathrm{~nm}$ of $1.37 \cdot 10^{5}$ and $1.09 \cdot 10^{5} \mathrm{M}^{-1} \cdot \mathrm{cm}^{-1}$, respectively (14). The enzymic activity was measured with maltose as substrate (52). $\mathrm{K}_{\mathrm{m}}$ and $\mathrm{V}_{\max }$ were determined from initial rates of hydrolysis of soluble starch at $37^{\circ} \mathrm{C}$ and maltose at $25^{\circ} \mathrm{C}$ both in $0.1 \mathrm{M}$-sodium acetate $\mathrm{pH} 4.3$ employing the concentration ranges $0.03-0.5 \%$ and $0.03-7.5$ $\mathrm{mM}$, respectively. Difference UV spectra were obtained as earlier reported (14). Contents of amino acids in acid hydrolysates were analysed on a Durrum D-500 amino acid analyzer (52). Nitrotyrosine was analysed spectrophotometrically (41). The incorporated EAC and ethylenimine were analysed as the corresponding products of acid hydrolysis, ethylamine and 2aminoethanol, eluting in the chromatogram of amino acids after arginine and before ammonia, respectively. Radioactivity was measured with an LKB model 1219 Rackbeta liquid scintillation counter using $5 \mathrm{ml}$ of Dimilume-30 as scintillant.

\section{RESULTS}

\subsection{Inactivation of glucoamylase with carbodiimides}

Carbodiimide readily reacts with a carboxylic acid to give $O$-acylisourea which undergoes acyl transfer to appropriate nucleophiles or rearranges to the less labile $N$-acylurea $(10,24,56)$. The time course for the inactivation of glucoamylase $\mathrm{G} 1$ from $A$. niger by EAC, EDC and $\mathrm{CMC}$ at $\mathrm{pH} 4.7$ in the second type of process is shown in Figure 1. EAC was clearly more reactive than the $\mathrm{CMC}$ and $\mathrm{EDC}$ which both had been employed in previous studics of fungal glucoamylases $(17,27,30,34)$. Under identical conditions glucoamylase $\mathbf{G} 2$ lost the activity at 2.3-fold the rate found for G1 (data not shown).

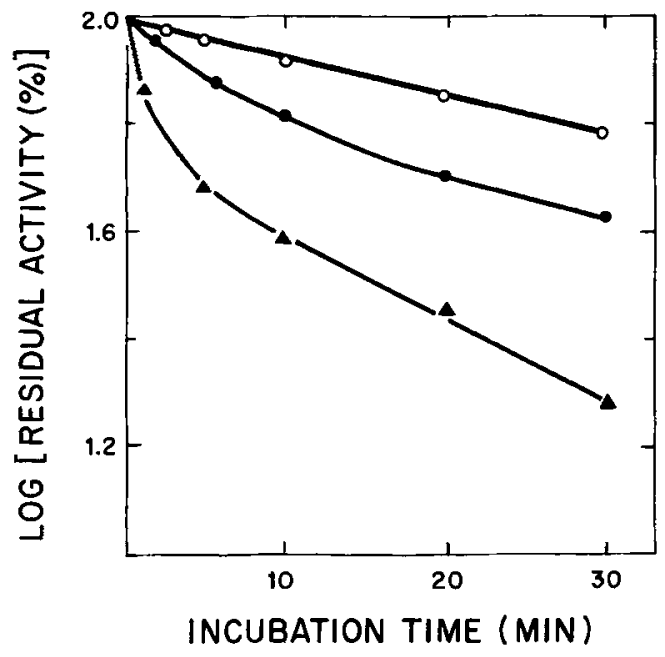

Figure 1. Inactivation of glucoamylase GI $(28 \mu \mathrm{M})$ by the water-soluble carbodiimides $\operatorname{EDC}(O), \mathrm{CMC}(\bullet)$, and $\mathrm{EAC}(\mathbf{A})$ (all at $5 \mathrm{~mm}$ ) at $\mathrm{pH} 4.7$.

A biphasic process was found for glucoamylase G1 (Fig. 2a) and G2 (data not shown) treated at pH 4.7, the second phase of inactivation following first-order kinetics with respect to enzyme. The inactivation of glucoamylase $\mathrm{G} 2$ at $\mathrm{pH} 6.0$ obeyed pseudo-first-order kinetics (Fig. 2b). However, at higher concentrations of reactants, the kinetics became complex (see section 3.2, Figs. 4 and 5). Conversion of both non-catalytic and catalytic groups was thus implicated to cause the decrease in activity. $\mathbf{k}_{\text {inact }}$ corresponding to the pseudo-first-order process (Fig. 2a and b) was proportional to [EAC] and the second-order rate constant for inactivation was determined to be $0.023 \mathrm{M}^{-1} \cdot \mathrm{s}^{-1}$ and $0.07 \mathrm{M}^{-1} \cdot \mathrm{s}^{-1}$ for glucoamylases $\mathrm{G} 2$ at $\mathrm{pH} 6.0$ and $\mathrm{Gl}$ at $\mathrm{pH} 4.7$, respectively. The same order of magnitude was reported for inactivation of other enzymes by EDC at the respective $\mathrm{pH}$ values $(26,55)$. A reaction order with respect to carbodiimide of 1.0 and 1.1 was calculated from the slope according to the method of LEVY et al. (35) for the G2 and G1 forms (Fig. 2a and b, inset), respectively. This suggested that modification by one equivalent of EAC is sufficient to abolish the activity.

The $\mathrm{pH}$-dependence of $\mathrm{k}_{\text {inact }}$ for glucoamylase G2 reflected the existence of a critical group of 

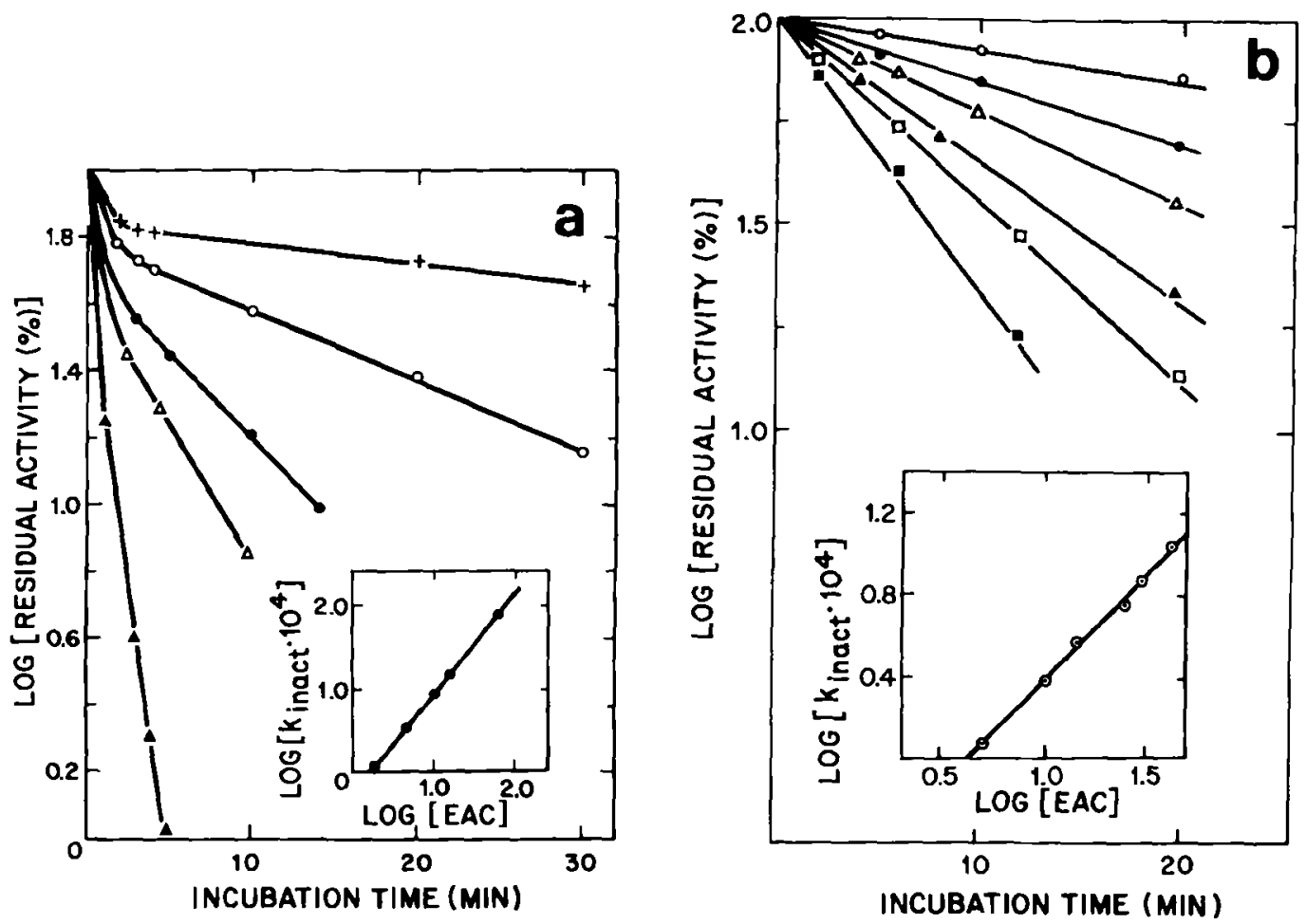

Figure 2. Inactivation of a) glucoamylase G1 $(24 \mu \mathrm{M})$ by EAC ( $2 \mathrm{~mm}:+; 5 \mathrm{~mm}: \mathrm{O} ; 10 \mathrm{~mm}:-; 17 \mathrm{~mm}: \Delta$ and 50 $\mathrm{mM}: \Delta)$ at pH 4.7 and b) glucoamylase $\mathrm{G} 2(11 \mu \mathrm{M})$ by EAC ( $5 \mathrm{mM}: 0 ; 10 \mathrm{mM}: \bullet ; 15 \mathrm{mM}: \Delta ; 25 \mathrm{mM}: \Delta, 30 \mathrm{~mm}$ : $\square$, and $45 \mathrm{~mm}: \mathrm{a})$ at $\mathrm{pH}$ 6.0. Inset: double-log plot of $\mathrm{k}_{\text {inact }} \mathrm{vs.}$ [EAC] $(35), \mathrm{k}_{\text {inec }}$ values were determined for the second phase of the semi-log plot in Fig. 2a.

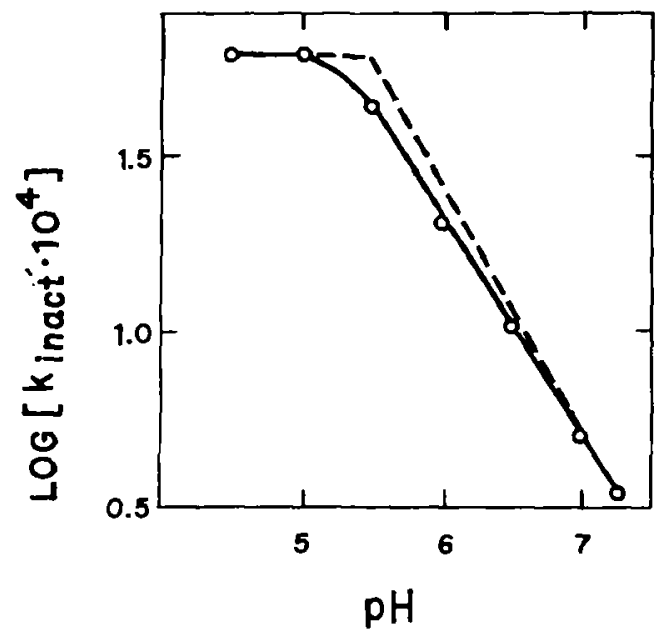

Figure 3. The $\mathrm{pH}$ dependence of inactivation of $\mathrm{G} 2$ ( 30 $\mu \mathrm{M})$ by EAC ( $39 \mathrm{~mm})$ in $0.1 \mathrm{M}$-Mes adjusted to the indicated $\mathrm{pH}$ values. $\mathbf{k}_{\text {inac }}$ values were obtained from semi-log plots of retained activity vs. time.
$\mathrm{pK}_{\mathrm{a}} 5.5$ (Fig. 3), conceivably the protonated form of either an aspartyl or a glutamyl residue. However, under the reaction conditions employed carbodiimides may also react with phenol and sulphydryl groups $(9,11)$. Tyrosines can be disregarded since $O$-arylisoureas are resistant to acid hydrolysis, and no loss of tyrosine was found by amino acid analysis. Furthermore, attempts to reactivate the enzyme derivative by $0.5 \mathrm{M}$-hydroxylamine failed (9). This is in accordance with the observation that acetylation of tyrosyl residues in A. niger glucoamylase has no influence on the rate of hydrolysis of soluble starch (25). It is also unlikely that the water-soluble carbodiimide modifies the single sulfhydryl group of this enzyme since this group is accessible for alkylation only after denaturation (B. SvENSSON, unpublished results).

The extent of the modification at $\mathrm{pH} 6.0$ was 
Table I. Ligand protection of glucoamylase G1

\begin{tabular}{lll}
\hline Ligand & $\begin{array}{l}\text { Concen- } \\
\text { tration } \\
(\mathrm{M})\end{array}$ & $\begin{array}{l}\text { Rate of inactivation } \\
\mathbf{k}_{\text {inac }} \\
\left(10^{4} \cdot \mathrm{s}^{-1}\right)\end{array}$ \\
\hline Maltose & 0.5 & 1.8 \\
Gluconolactone & 0.1 & 4.4 \\
Maltitol & 0.3 & 5.9 \\
Acarbose & 0.003 & 1.1 \\
None & & 7.9 \\
\hline
\end{tabular}

G1 $(31 \mu \mathrm{M})$ was treated with EDC $(75 \mathrm{~mm})$ and glycine ethyl ester $(0.7 \mathrm{M})$ at $\mathrm{pH} 4.7$ in the presence of various ligands. The progress of inactivation was followed by measuring remaining activity towards maltose. The $k_{\text {inact }}$ values were determined from semi-log plots.

assessed (see 2.2.2) for inactivated glucoamylases, purified from the reaction mixtures by gel filtration on Bio-Gel P-100 in $0.2 \mathrm{M}-\mathrm{NH}_{4} \mathrm{HCO}_{3}$, to 23 and 16 EAC-labelled residues in the $\mathrm{Gl}$ and $\mathrm{G} 2$ forms possessing 71 and 54 acidic groups $(6,48,50)$, respectively. After treatment at $\mathrm{pH}$ 4.7 the corresponding numbers were 30 and 20 EAC groups incorporated.

\subsection{Effect of ligands during carbodiimide treatment}

The accessibility of essential carboxyl groups in glucoamylase was tested by reacting the enzyme with a fixed concentration of EDC and glycine ethyl ester at $\mathrm{pH} 4.7$ in the presence of various specific ligands. The $\mathrm{k}_{\text {inact }}$ values (Table I) reflected the tight-binding inhibitor acarbose (57) to be superior to the substrate maltose as protective agent while both a transition state analogue gluconolactone and a competitive inhibitor maltitol $(21,23)$ provided marginal protection. The effect of acarbose was concentration-dependent (Fig. 4). A plot of $k_{\text {inact }}$ values for the second phase was constructed according to SCRUTTON and UTTER (43) and gave a straight line that extrapolated through the origin (inset, Fig. 4). This indicated that the acarbose-glucoamylase complex would not be inactivated by EAC. The $K_{d}$ for this complex formation was calculated from the slope (43) to be $4 \mu \mathrm{M}$ which is in reasonable agreement with the value of 1

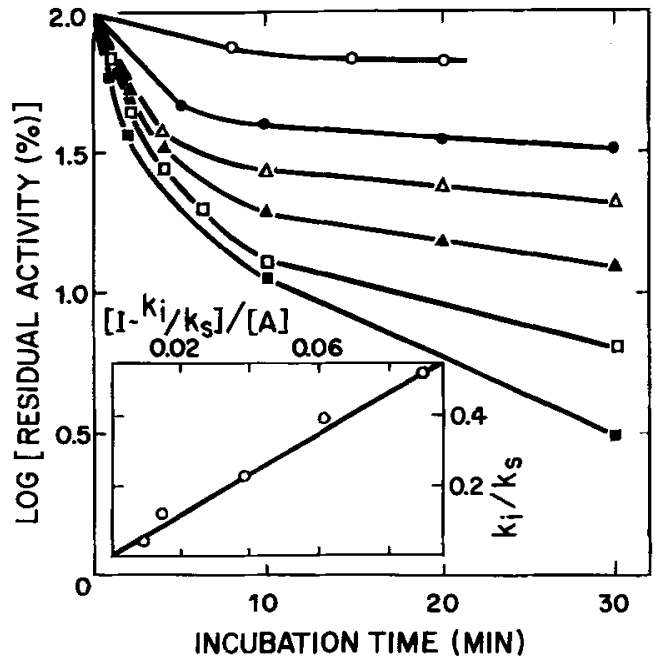

Figure 4. Inactivation of glucoamylase $\mathrm{G} 2(20 \mu \mathrm{M})$ by EAC ( $54 \mathrm{mM})$ at pH 6.0 in the absence ( $\square)$ and in the presence of acarbose $2.5(\square), 5.0(\Delta), 10(\Delta), 30(0)$ and $100(\mathrm{O}) \mu \mathrm{g} \cdot \mathrm{ml}^{-1}$. Inset: the observed pseudo-firstorder rate constants for the second phase of inactivation in the absence $\left(k_{s}\right)$ and in the presence of inhibitor $\left(k_{i}\right)$ have been plotted according to SCRUTTON and UTTER (43) as a function of [acarbose] $\left(\mathrm{A}\right.$, in $\left.\mu \mathrm{g} \cdot \mathrm{ml}^{-1}\right)$.

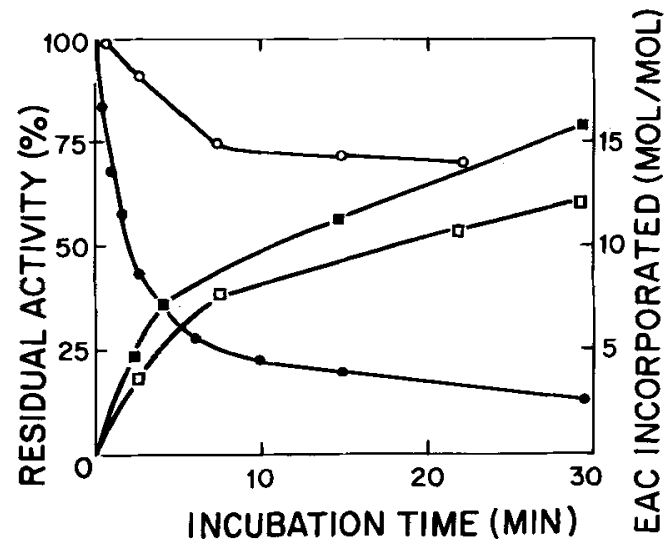

Figure 5. Inactivation of glucoamylase $\mathrm{G} 2(20 \mu \mathrm{M})$ by EAC (54 mM) in the presence $(O)$ and absence $(\theta)$ of acarbose $(0.13 \mathrm{~mm})$ at $\mathrm{pH} 6.0$. The corresponding incorporation of $\mathrm{EAC}$ ( $\square$ and $\square$ ) was estimated as described in section 2.2.2. 
$\mu \mathrm{M}$ determined earlier by fluorescence quenching (14).

Since acarbose drastically slows down modification of essential carboxyl group(s) it is very suitable for differential labelling of glucoamylase (see 3.4). Treatment of the $\mathrm{G} 2$ form with 54 $\mathrm{mM}$-EAC in the presence of $0.13 \mathrm{~mm}$-acarbose thus led to covalent labelling of 12 residues with concomitant retention of $70 \%$ of the initial activity after removal of ligand (Fig. 5). In the absence of acarbose, substitution of 16 residues concurred with loss of $90 \%$ of the activity. Similar results were obtained for glucoamylase Gl (not shown).

\subsection{Characterization of EAC-modified glucoamylase}

Specific ligands perturbed the UV absorption spectrum of glucoamylase $\mathrm{G} 2$ both before and after the modification with EAC (Table II). The environment of tryptophan(s) involved in complex formation, however, had clearly been altered even in the catalytically active derivative prepared in the presence of acarbose (see 3.2). The $\Delta \varepsilon_{294}$ due to acarbose pertubation was thus reduced from $1,740 \mathrm{M}^{-1} \cdot \mathrm{cm}^{-1}$ to $470 \mathrm{M}^{-1} \cdot \mathrm{cm}^{-1}$ as a consequence of the modification (Table II). Furthermore, a peak near $300 \mathrm{~nm}$ in the UV difference spectrum, which is normally attributed to the influence of a negative charge on tryptophan $(1,2)$, was essentially eliminated in the acarbose-induced difference spectra for the enzyme derivatives (Table II). This suggested that EAC converted a carboxylic acid located at or near a ligand binding region to a positively charged $N$-acylurea. In addition, the ability to bind maltose was retained in the derivatives. However, in contrast to their distinctly different effects on the unmodified enzyme, acarbose and maltose induced very similar difference spectra for the derivatives (Table II). It may thus be inferred that an exposed carboxyl group is connected with an acarbose-binding region situated outside of the subsites 1 through 3 occupied by maltose (21). Modification of the catalytic site caused a decrease in perturbation at $285-287 \mathrm{~nm}$ which may reflect reduced accessibility to both tryptophanyl and tyrosyl chromophores.

The catalytically active glucoamylase deriva- 
Table III. Kinetic parameters of EAC-treated glucoamylase G2

\begin{tabular}{|c|c|c|c|c|}
\hline Substrate & Solut & starch & Mal & tose \\
\hline Enzyme & $\mathrm{K}_{\mathrm{m}}(\%)$ & $\max \left(s^{-1}\right)$ & $\mathrm{K}_{\mathrm{m}}(\mathrm{mM})$ & $V_{\max }\left(s^{-1}\right)$ \\
\hline G2 & 0.05 & 38 & 1.7 & 2.5 \\
\hline EAC-G2 & 0.11 & 33 & 2.2 & 1.8 \\
\hline
\end{tabular}

Assay conditions are described in 2.2 .2 and the derivative in 3.2 .

tive displayed increased $K_{m}$ and reduced $V_{\max }$ values as compared to the unmodified enzyme (Table III). The largest effect was the doubling of $\mathrm{K}_{\mathrm{m}}$ for starch hydrolysis, reflecting perhaps changes in substrate binding subsite(s) at a distance from the catalytic site.

\subsection{Differential labelling of essential carboxyl groups}

Acarbose was tested as protective ligand (see also 3.2) in differential labelling experiments. Remodification with $21 \mathrm{mM}-\left[{ }^{3} \mathrm{H}\right] \mathrm{EAC}$ of a catalytically active derivative of glucoamylase $\mathrm{G} 2$, prepared as described (see 2.2.1 and 3.2), reduced its activity in a pseudo-first-order process to $5 \%$ concurrent with an average incorporation of $3.4\left[{ }^{3} \mathrm{H}\right] \mathrm{EAC}$ groups per enzyme molecule (data not shown).

In spite of the poorer protection of the enzyme by maltose (Table I) attempts were made also for differential labelling utilizing this substrate $(0.6 \mathrm{M})$. In this situation EDC and glycine ethyl ester $(0.7 \mathrm{M})$ reacted with approx. 36 of the 71 carboxyl groups $(6,51)$ in glucoamylase G1 and $55 \%$ of the enzymic activity was retained (Fig. 6). When maltose was removed, repeated treatment resulted in additional incorporation of approx. 2 molecules of glycine ethyl ester accompanied by reduction of the activity to $8 \%$. When the pretreated and partially active derivative instead was incubated with EDC and either $\left[{ }^{14} \mathrm{C}\right]$ glycine ethyl ester $(5 \mathrm{mM})$ or nitrotyrosine ethyl ester $(30 \mathrm{~mm})$ complete inactivation and incorporation of 0.2 and 0.3 equivalents of the respective nucleophiles were achieved. Even more surprisingly, when EDC and norleucine methyl ester $(0.7 \mathrm{M})$ were employed in the

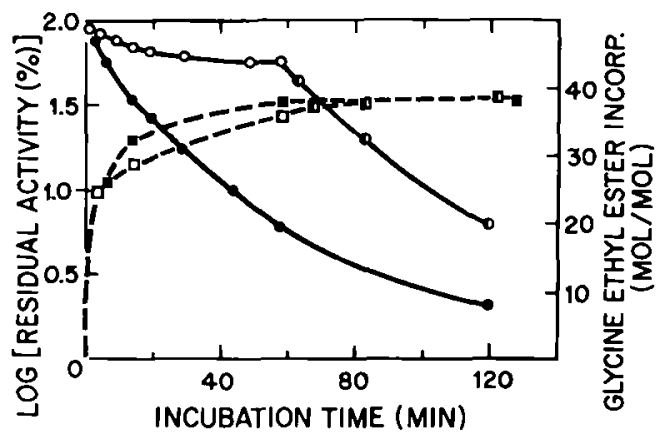

Figure 6. Inactivation of glucoamylase $\mathrm{G} 1(43 \mu \mathrm{M})$ by EDC $(75 \mathrm{mM})$ and glycine ethyl ester $(0.7 \mathrm{M})$ in the absence $(\Theta)$ and in the presence $(O)$ of maltose $(0.6 \mathrm{M})$ in $0.1 \mathrm{M}-\mathrm{Mes} \mathrm{pH}$ 4.7. The incorporation of glycine ethyl ester in the absence ( $\square$ ) and presence ( $\square$ ) of maltose was estimated by amino acid analysis (see 2.2.2). Maltose was removed after $60 \mathrm{~min}$. The enzyme derivative was isolated (see 2.2.1) and subsequently inactivated (D) by treatment with EDC and glycine ethyl ester incorporation (D) as in the first modification step.

second step, 6 nucleophile residues were incorporated without affecting the activity. Thus, combination of these non-essential side chains with norleucine methyl ester apparently hindered inactivation, whereas the nucleophiles added in much lower concentration in the two former experiments seemed unable to compete with inactivation through the $O$-acylisourea to $\mathrm{N}$-acylurea rearrangement. Similar observations have been documented in other studies (3), including Rhizopus glucoamylase Gluc , modi- $^{-}$ fied by CMC and taurine (30).

In view of the ambiguity by the differential labelling of protected carboxyl groups in A. niger glucoamylase by the various easily detected nucleophiles, EAC and $\left[{ }^{3} \mathrm{H}\right] \mathrm{EAC}$ became the reagents of choice for preparative-scale experiments (47) despite the inferior stability of the $N$-acylurea product relative to amides, generated by nucleophilic attack on $O$-acylisourea derivatives by amino compounds $(10,24)$. When maltose and acarbose were employed as protective agent, the subsequent inactivation of both glucoamylase G1 and G2 occurred with concomitant incorporation of 2 and 3-4 $\left[{ }^{3} \mathrm{H}\right] \mathrm{EAC}$ groups, respectively. This is in agree- 
Table IV. Effect of ethylenimine on glucoamybase G1

\begin{tabular}{lcll}
\hline $\begin{array}{l}\text { Enzyme } \\
(\mu \mathrm{M})\end{array}$ & $\begin{array}{l}\text { Ethylenimine } \\
(\mathrm{mM})\end{array}$ & $\begin{array}{l}\text { Incorporated } \\
\text { ethylenimine/enzyme } \\
(\mathrm{mol} / \mathrm{mol})\end{array}$ & $\begin{array}{l}\text { Activity retained } \\
(\%)\end{array}$ \\
\hline 240 & 7.5 & 0.80 & 44 \\
98 & 7.5 & 0.87 & 44 \\
37 & 7.5 & 0.87 & 41 \\
12 & 7.5 & 1.5 & 37 \\
600 & 41 & 2.3 & 29 \\
600 & 110 & 3.3 & 22 \\
600 & 170 & 3.3 & 21 \\
600 & 820 & 6.7 & 18 \\
\hline
\end{tabular}

The conditions for modification are described in 2.2.1. The extent of incorporation was analyzed after acid hydrolysis, and the activity was measured with maltose as substrate (2.2.2).

ment with the differential labelling of the Gl form by EDC and 0.7 M-glycine ethyl ester (Fig. 6).

\subsection{Inactivation of glucoamylase by ethylenimine}

Incorporation of approx. 1 molar equivalent of ethylenimine in glucoamylase caused loss of up to $60 \%$ of the enzymic activity (Table IV). However, complete inactivation was not achieved by incorporation of a further 7 groups. Similar findings have been obtained previously with lysozyme. In this case, two different types of enzyme derivatives with singly modified catalytic carboxyl groups, Asp52 or Glu35 (5), could be identified (58). Evidence for a selective reaction of ethylenimine with essential carboxyl groups has thus been demonstrated for two carbohydrases, a behaviour perhaps promoted by the basic character of the compound.

\section{DISCUSSION}

Since its introduction as a reagent for chemical modification of proteins by KOSHLAND and coworkers $(10,24,40)$ carbodiimides have been successfully employed for probing the role of acidic amino acid residues in the function of proteins (for a recent review see ref. 36). Among the many carbohydrases studied several reports described the use of carbodiimides in character- ization of fungal glucoamylases $(17,27,30,34$, 42). In the present study attempts have been made to distinguish different categories of functionally important carboxyl groups in A. niger glucoamylase and a procedure enabling specific labelling of 2-4 critical residues has been established.

Of the various carbodiimides tested EAC proved to be the most useful. This reagent readily forms the $N$-acylurea derivative of protein carboxyl groups (56) since, unlike EDC, it cannot undergo the stabilizing tautomerization to unreactive cyclic forms (54). Compared with other water-soluble carbodiimides, EAC has been utilized relatively little, previous studies comprising the characterization of cytochrome $c$ oxidase (38), enolase (16), cellulase (13) and thrombin (12). The present results underline the advantages in employing EAC for labelling of carboxylic acid residues.

As the possible reaction of carbodiimide with phenol and thiol groups in A. niger glucoamylase can be excluded, the inactivation of the enzyme can be ascribed to modification of aspartyl/glutamyl residues. Moreover, the $\mathrm{pH}$ dependence of the inactivation by EAC closely resembles the $\mathrm{pH}$-activity profiles previously published for fungal glucoamylases $(20,22,42)$. In the present work a pK $=5.5$ was indicated in consistency with kinetic evidence pointing at two carboxyl groups $(20,22)$ in the active site. The values $\mathrm{pK}_{1}=2.75$ and $\mathrm{pK}_{2}=5.55$ have been 
reported for the glucoamylase from A. awamori (42) which is identical to the A. niger enzyme.

Similar to $N$-bromosuccinimide oxidation of tryptophans in A. niger glucoamylases (14, 15) acarbose proved in the present work to confer the best protection of essential carboxyl groups. However, both maltose and acarbose were unable to prevent the initial decrease in activity during the treatment with carbodiimide. A similar trend was reported by others $(17,27$, 34) and it is suggested that exposed and readily reacting non-catalytic carboxyl groups were modified first while the catalytic group(s) reacted in the second phase leading to almost complete inactivation. Still, the second-order rate constants for the latter phase were not unusually low, consistent with the suggestion that the rearrangement to $N$-acylurea is promoted for partially buried $O$-acylisourea intermediates $(38,56)$. Acarbose $(57)$ is a pseudotetrasaccharide and probably associates with subsites 1 through 4 of glucoamylase $(14,46)$. In analogy with other carbohydrase-ligand complexes (5, 37) it is assumed to hydrogen-bond via sugar hydroxyl groups to carboxyl and other groups that line the extended binding cleft. In addition, it interacts with the catalytic carboxylic acid residue(s). Accordingly, the enzyme derivative obtained in the presence of acarbose not only retained the ability to bind various specific ligands, but also expressed $70-80 \%$ of the original catalytic activity. In fact, only relatively small effects on the kinetic parameters were observed for the modified and partially active enzyme. Ligands, furthermore, induced UV difference spectra with peaks at $285-287 \mathrm{~nm}$ and 292-294 nm. This indicated that both tryptophanyl and tyrosyl residues $(18,19)$ are involved in complex formation as observed for unmodified enzyme, although lack of a peak near $300 \mathrm{~nm}$ in acarbose-induced difference spectra implied alteration of a subsite at a distance from the catalytic site (see 3.3). The ligand-complexation observed even for the inactive enzyme derivative is in agreement with an earlier report on maltose protecting tryptophans against photooxidation after inactivation of the enzyme with EDC and glycine methyl ester (31).

The employment of EAC has two advantages, it is readily prepared in a radioactive form allowing for the facile identification of differentially labelled residues and the quarternary ammonium group of the EAC only causes a slight decrease in the solubility of the modified enzyme. In order to reduce the overall extent of the modification of catalytically uninteresting groups, the treatment was performed at pH 6.0 rather than at $\mathrm{pH} 4.7$. This also favours labelling of carboxyl groups with higher $\mathrm{pK}_{\text {, values (12) }}$ such as the putative general-acid catalytic residue.

Differential labelling of glucoamylase from $A$. niger with $\left[{ }^{3} \mathrm{H}\right] \mathrm{EAC}$ after prior modification with cold reagent in the presence of either acarbose or maltose led to specific labelling of about 3-4 or 2 carboxylic acid residues, respectively. In comparison, a total of only three carboxyl groups out of 38 reacted with CMC in glucoamylase Gluc $_{1}$ from Rhizopus sp. and maltose protection suggested that one group is critical for the activity (30). In Gluc $\mathrm{M}_{1}$ and Gluc $M_{2}$ from A. saitoi 12 and 5 CMC groups were incorporated and maltose protected 2 and 1 carboxyl groups, respectively. Upon removal of maltose, 4 and 2 additional CMC could be incorporated $(27,34)$. No attempts, however, have been reported on identification of the protected residues in the sequence of these fungal glucoamylases containing relatively few reactive groups. We have therefore undertaken the identification and assignment of roles in binding and catalysis of essential carboxylic acid residues in glucoamylase $G 2$ from $A$. niger by sequencing covalently labelled peptide fragments as to be described elsewhere (47).

\section{ACKNOWLEDGEMENTS}

We are indebted to Professor Martin OT. TESEN for his support throughout the present study. The generous participation and advice of Dis. JøRn DalgaARd Mikkelsen, De Danske Sukkerfabrikker A/S, Copenhagen, and C.L. BORDERS, Department of Chemistry, College of Wooster, Ohio in synthesis of $\left[{ }^{3} \mathrm{H}\right] \mathrm{EAC}$ is gratefully acknowledged. Ms EDITH FLøISTRUP is thanked for expert technical assistance. Ms BODIL CORNELIUSSEN is acknowledged for the amino acid analyses. Drs. E. Truscheit, D. SCHMIDT, and G. MOLleR, Bayer A.G., Wupper- 
tal, FRG are thanked for the gift of acarbose, and Dr. HaNNE EgGERT, Chemical Laboratory II, University of Copenhagen, for performing

${ }^{13} \mathrm{C}-\mathrm{NMR}$-analysis of EAC.

\section{REFERENCES}

1. Ananthanarayanan, V.S. \& C.C. Bigelow: Unusual difference spectra of proteins containing tryptophan. I. Studies with model compounds. Biochemistry 8, 3717-3723 (1969)

2. Ananthanarayanan, V.S. \& C.C. Bigelow: Unusual difference spectra of proteins containing tryptophan. II. Studies with proteins. Biochemistry 8, 3723-3728 (1969)

3. ARIKI, M.\& T. FUKUI: Modification of rabbit muscle phosphorylase $b$ by a water-soluble carbodiimide. J. Biochem. 83, 183-190 (1978)

4. AShikari, T., N. Nakamura, Y. Tanaka, N. KIUChI, Y. Shibano, T. Tanaka, T. Amachi \& $\mathrm{H}$. YoshIzUMI: Rhizopus raw-starch-degrading glucoamylase: its cloning and expression in yeast. Agric. Biol. Chem. 50, 957-964 (1986)

5. BLAKE, C.C.F., L.N. Johnson, G.A. MaIR, A.C.T. North, D.C. Phillips \& V.R. Sarma: Crystallographic studies of the activity of hen egg-white lysozyme. Proc. Roy. Soc. SerB 167, 378-387 (1967)

6. Boel, E., I. Huort, B. Svensson, F. Norris, K.E. NORRIS \& N.P. FilL: Glucoamylases G1 and G2 from Aspergillus niger are synthesized from two different but closely related mRNAs. EMBO J. 3, 1097-1102 (1984)

7. Braun, H., A. Cogoli \& G. Semenza: Carboxyl groups at the two active centers of sucrase-isomaItase from rabbit small intestine. Eur. J. Biochem. 73, 437-442 (1977)

8. Buisson, G., E. Dué, R. Haser \& F. Payan: Three dimensional structure of porcine pancreatic $\alpha$ amylase at $2.9 \dot{\mathrm{A}}$ resolution. Role of calcium in 、 structure and activity. EMBO J. 6, 3908-3916 (1987)

9. Carraway, KLL \& D.E. Koshland JR.: Reaction of tyrosine residues in proteins with carbodiimide reagents. Biochim. Biophys. Acta. 160, 272-274 (1968)

10. Carraway, KL. \& D.E. Koshland JR.: Carbodiimide modification of proteins. Meth. Enzymol. 25, 616-623 (1972)

11. Carraway, KL. \& R.B. TRIPLetr: Reaction of carbodiimides with protein sulphydryl groups. Biochim. Biophys. Acta 200, 564-566 (1970)

12. Chan, V.W.F., A.M. JoRgensen \& C.L. Borders

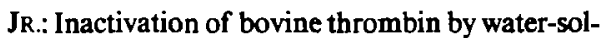

uble carbodiimides: the essential carboxyl group has a pK, of 5.51. Biochem. Biophys. Res. Commun. 151, 709-716 (1988)

13. ClaRKE, A.J. \& M. YaGUCHI: The role of carboxyl groups in the function of endo- $\beta-1,4-$ glucanase from Schizophyllum commune. Eur. J. Biochem. 149, 233-238 (1985)

14. Clarke, A.J. \& B. Svensson: The role of tryptophanyl residues in the function of Aspergillus niger glucoamylase $\mathrm{G} 1$ and G2. Carlsberg Res. Commun. 49, 111-122 (1984)

15. Clarke, A.J. \& B. Svensson: Identification of an essential tryptophanyl residue in the primary structure of glucoamylase G2 from Aspergillus niger. Carlsberg Res. Commun. 49, 559-566 (1984)

16. GEORGE, JR. A.L. \& C.L. Borders JR.: Essential carboxyl residues in yeast enolase. Biochem. Biophys. Res. Commun. 87, 59-65 (1979)

17. GRAY, C.J. \& M.E. JolleY: The role of carboxylic acid groups in the action of glucoamylase I. FEBS lett. $29,197-200$ (1973)

18. HerSkovits, T.T. \& SR. M. SORENSEN: Studies of the location of tyrosyl and tryptophyl residues in proteins. I. Solvent pertubation data of model compounds. Biochemistry 7, 2523-2542 (1968)

19. HERSKOVITS, T.T. \& SR. M. SORENSEN: Studies of the location of tyrosyl and tryptophyl residues in protein. II. Applications of model data to solvent pertubation studies of proteins rich in both tyrosine and tryptophan. Biochemistry 7, 2533-2542 (1968)

20. Hiromi, K, M. KaWAI \& S. ONo: Kinetic studies on gluc-amylase. IV. Hydrolysis of isomaltose. J. Biochem. 59, 476-480 (1966)

21. Hiromi, K, M. OhNishi \& A. TanaKa: Subsite structure and ligand binding mechanism of glucoamylase. Mol. Cell. Biochem. 51, 79-95 (1983)

22. Hiromi, $\mathrm{K} \& \mathrm{~S}$. ONO: Kinetic studies on gluc-amylase. III. The influence of $\mathrm{pH}$ on the rates of hydrolysis of maltose and panose. J. Biochem. 59, 469-475 (1966)

23. Hiromi, K, A. TaNaKa \& M. OHNISHI: Fluorometric studies on the binding of gluconolactone, glucose and glucosides to subsites of glucoamylase. Biochemistry 21, 102-107 (1982)

24. HOARE, D.G. \& D.E. KoshLAND JR.: Method for the quantitative modification and estimation of carboxylic acid groups in proteins. J. Biol. Chem. 242, 2447-2453 (1967)

25. HOSCHKE, A., E. LASZLO \& J. Hollo: A study of the role of tyrosine groups at the active centre of amylolytic enzymes. Carbohydr. Res. 81, 157-166 (1980)

26. INANO, H.\& B. TAMAOKI: The presence of essential carboxyl group for binding of cytochrome $c$ in rat 
hepatic NADPH-cytochrome $P-450$ reductase by the reaction with 1-ethyl-3-(3-dimethylaminopropyl)carbodiimide. J. Enzyme Inhibition 1, 47-59 (1985)

27. INOKUCHI, N., M. IWAMa, T. TAKOHASHI \& M. IRIE: Modification of a glucoamylase from Aspergillus saitoi with 1-cyclohexyl-3(2-morpholinyl-(4)ethyl)carbodiimide. J. Biochem. 91, 125-133 (1982)

28. ISODA, Y.\& Y. NITTA: Affinity labeling of soybean $\beta$-amylase with 2',3'-epoxypropyl $\alpha$-D-glucopyranoside. J. Biochem. 99, 1631-1637 (1986)

29. IтoH, T., I. Ohtsuki, I. Yamashita \& S. Fukui: Nucleotide sequence of the glucoamylase gene GLU1 in the yeast Saccharomycopsis fibuligera. J. Bacteriol. 169, 4171-4176 (1987)

30. IWAMa, M., R. OHTSUKI, T. TAKOHaShI \& M. IRIE: Modification of glucoamylases from Rhizopus sp. with 1-cyclohexyl-3-(2-morpholinyl-(4)-ethyl)carbodiimide. J. Biochem. 96, 329-336 (1984)

31. JOLLEY, M.E. \& C.J. GRAY: Tryptophanyl and carboxylic acid residues in the active centre of glucoamylase I from Aspergillus niger. Carbohydr. Res. 49, 361-370 (1976)

32. Kanaya, K, S. Chiba \& T. Shimomura: Inactivation of buckwheat $\alpha$-glucosidase with 1-ethyl-3-(3dimethylaminopropyl)carbodiimide. Agric. Biol. Chem. 43, 1841-1847 (1979)

33. KoCHHAR, S. \& R.D. DUA: An active-site carboxyl group in liquefying $\alpha$-amylase: specific chemical modification. Biosci. Rep. 4, 613-619 (1984)

34. Koyama, T., N. InOKuChI, M. IWAma \& M. IRIE: Modification of a minor glucoamylase from Aspergillus saitoi with 1-cyclohexyl-3-(2-morpholinyl-(4)-ethyl)carbodiimide. J. Biochem. 97, 633-641 (1985)

35. LEVY, H.M., P.D. LEBER \& E.M. RYAN: Inactivation of myosin by 2,4-dinitrophenol and protection by adenosine triphosphate compounds. J. Biol. Chem. 238, 3654-3659 (1963)

36. LUNDBLAD, R.L. \& C.M. NOYes: In: Chemical Reagęnts for Protein Modification. (CRC Press, Inc. 1984, Boca Raton, FL) pp. 105-121

37. Matsuura, Y., M. Kusunoki, W. Harada \& $M$. KAKUDO: Structure and possible catalytic residues of Taka-amylase A. J. Biochem. 95, 697-702 (1984)

38. Millett, F., C. De Jong, L. Paulson \& R.A. CaPALDI: Identification of specific carboxylate groups on cytochrome $c$ oxidase that are involved in binding of cytochrome $c$. Biochemistry 22, 546552 (1983)

39. Plant, A.R., R.M.Clemens, H.W. Morgan \& R.M. DANIEL: Active-site- and substrate-specificity of Thermoanaerobium Tok6-B1 pullulanase. Bio- chem. J. 246, 537-541 (1987)

40. RIEHM, J.P. \& H.A. SHERAGA: Structural studies of ribonuclease. XXI. The reaction between ribonuclease and a water-soluble carbodiimide. Biochemistry 5, 99-115 (1966)

41. RIORDAN, J.F. \& B.L. VALLEE: Nitration with tetranitromethane. Meth. Enzymol. 25, 515-521 (1972)

42. SAVEL'EV, A.N. \& L.M. Firsov: Effect of modification of some amino acid radicals on enzymatic activity of glucoamylase from Aspergillus awamori. Biokhimiya 48, 1311-1318 (1983)

43. SCRUTTON, M.C. \& M.F. UTTER: Pyruvate carboxylase. V. Interaction of the enzyme with adenosine triphosphate. J. Biol. Chem. 240, 3714-3723 (1965)

44. Sheenan, J.C., P.A. Cruickshank \& G.L. Boshart: A convenient synthesis of water-soluble carbodiimides. J. Org. Chem. 26, 2525-2528 (1961)

45. Svensson, B.: Regional distant sequence homology between amylases, $\alpha$-glucosidases and transglucanosylases. FEBS Lett. 230, 72-76 (1988)

46. SVENSSON, B., A.J.Clarke \& I. SvendSEN: Influence of acarbose and maltose on the reactivity of individual tryptophanyl residues in glucoamylase from Aspergillus niger. Carlsberg Res. Commun. 51, 61-73 (1986)

47. Svensson, B., A.J. Clarke, I. Svendsen \& H. MøLLER: Identification of carboxylic acid residues in glucoamylase $\mathrm{G} 2$ from Aspergillus niger that are involved in catalysis and substrate binding. (in prep.)

48. Svensson, B., A.J.Clarke, H. Møller, I.Svendsen \& K. HÁKANSSON: Identification of amino acid residues essential for catalysis and substrate binding in A. niger glucoamylase. XIIIth International Carbohydrate Symposium, Cornell, Ithaca, N.Y. (1986)

49. Svensson, B., K. Larsen, \& A. Gunnarsson: Characterization of a glucoamylase G2 from Aspergillus niger. Eur. J. Biochem. 154, 497-502 (1986)

50. Svensson, B., K. LaRSEn \& I. SVendsen: Amino acid sequence of tryptic fragments of glucoamylase Gl from Aspergillus niger. Carlsberg Res. Commun. 48, 517-527 (1983)

51. SVensson, B., K LaRSEN, I. SVEndSen \& E. Boel: The complete amino acid sequence of the glycoprotein, glucoamylase G1 from Aspergillus niger. Carlsberg Res. Commun. 48, 529-544 (1983)

52. SVEnsson, B., T.G. Pedersen, I. SVEndSen, T. SAKai \& M. OTTESEN: Characterization of two forms of glucoamylase from Aspergillus niger. Carlsberg Res. Commun. 47, 55-69 (1982)

53. Tanaka, Y., T. Ashikari, N. Nakamura, N. KIUChI, Y. Shibano, T. Amachi \& H. Yoshizumi: Comparison of amino acid sequence of three 
glucoamylases and their structure-function relationships. Agric. Biol. Chem. 50, 965-969 (1986)

54. TENFORDE, T., R.A. FAWWAZ \& N.K. FREEMAN: Nuclear magnetic resonance and infrared studies on the tautomerism of 1-ethyl-3-(3-dimethylaminopropyl)carbodiimide. J. Org. Chem. 37, 33723374 (1972)

55. Terra, W.R., I.C.M. Terra, C. Ferreira \& A.G. DE BIANCHI: Carbodiimide-reactive carboxyl groups at the active site of an insect midgut trehalase. Biochim. Biophys. Acta 57, 79-85 (1979)

56. TIMKovich, $\mathbf{R}$ : Detection of the stable addition of carbodiimide to proteins. Anal. Biochem. 79, 135143 (1977)

57. Truschert, E., W. Frommer, B. Junge, L. Müller, D.D. SCHMidT \& W. Wingender: Chemie und Biochemie mikrobieller $\alpha$-Glucosidasen-Inhibitoren. Angew. Chem. 93, 738-755 (1981)
58. Y AMADA, H., T. ImOTo \& S. NoshiTA: Modification of catalytic groups in lysozyme with ethyleneimine. Biochemistry 21, 2187-2192 (1982)

59. Yamashita, I., M. Nakamora \& S. FukUi: Gene fusion is a possible mechanism underlying the evolution of STA1. J. Bacteriol. 169, 2142-2149 (1987)

60. Yamashita, I., K SuzUKI \& S. FuKui: Nucleotide sequence of the extracellular glucoamylase gene STA1 in the yeast Saccharomyces diastaticus. J. Bacteriol. 161, 567-573 (1985)

61. YANG, S., S. GE, Y. ZENG \& S. ZHANG: Inactivation of $\alpha$-glucosidase by the active-site-directed inhibitor, conduritol B epoxide. Biochim. Biophys. Acta 828, 236-240 (1985)

Accepted by H. KLENOW 